\title{
21st century learning environments
}

Todd, A ; Boivin, P ; Ramírez, J B ; Surian, A ; Markauskaite, L ; Billett, S ; Kaye, T ; Hofmann, R ; Felix, S ; Tomasik, Martin ; van Campen, C ; Koh, E ; Gegenfurtner, A ; Newell, S ; Wijnia, L ;

Muukkonen, $\mathrm{H}$; Detienne, L

Posted at the Zurich Open Repository and Archive, University of Zurich

ZORA URL: https://doi.org/10.5167/uzh-179455

Monograph

Published Version

Originally published at:

Todd, A; Boivin, P; Ramírez, J B; Surian, A; Markauskaite, L; Billett, S; Kaye, T; Hofmann, R; Felix, S; Tomasik, Martin; van Campen, C; Koh, E; Gegenfurtner, A; Newell, S; Wijnia, L; Muukkonen, H; Detienne, L (2019). 21st century learning environments. Bruxelles: Life Long Learning Platform. 


\section{ST CENTURY \\ LERRNING \\ ENVIRONIMENTS}

\section{LLLP - POSITION PAPER - 2019}

LIFELONG

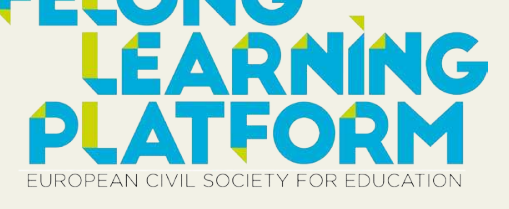

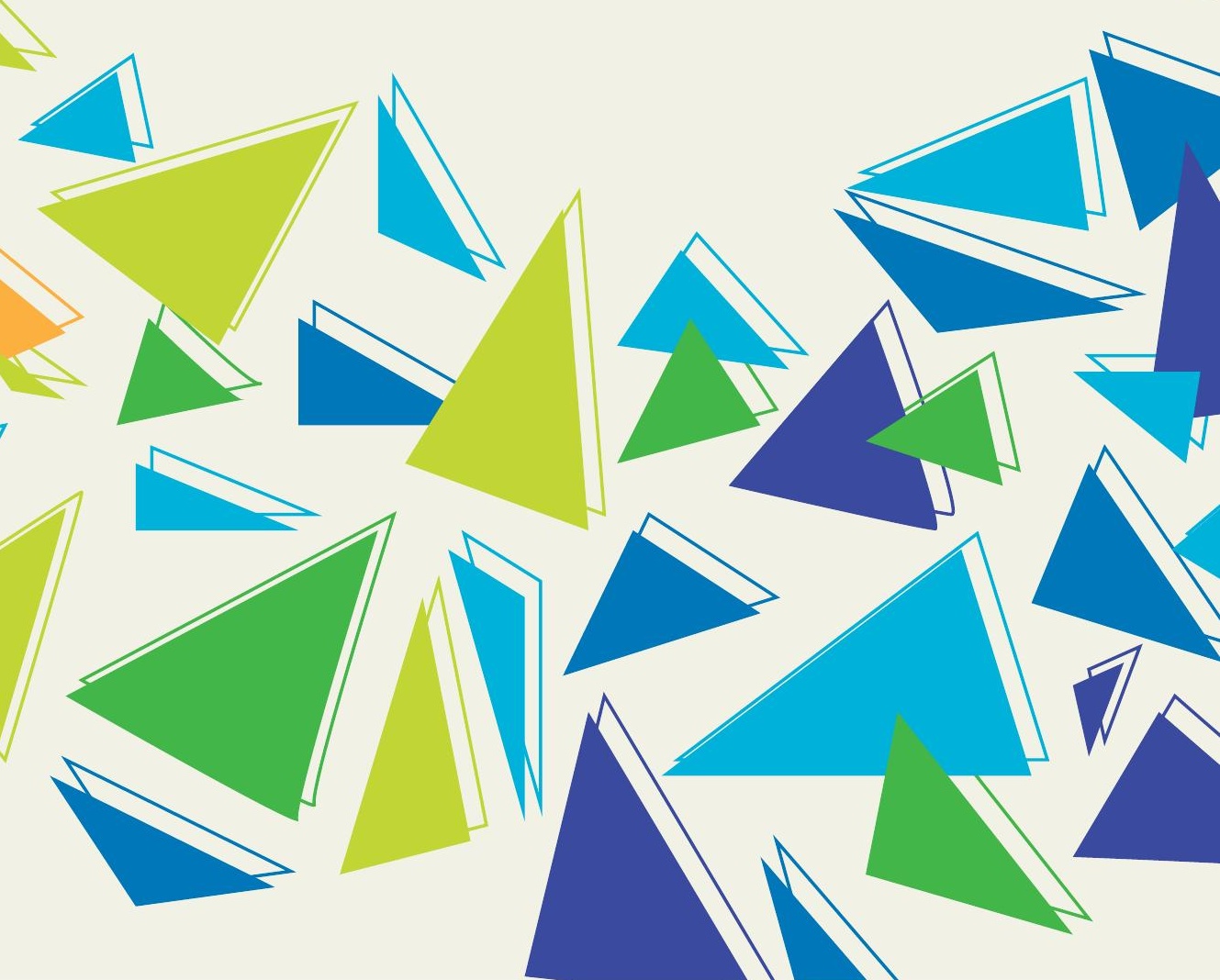


Shifting from education to learning: all learning made equal

$>21$ st century, so what? Space, time, and societal transformation

$>$ Local communities: a shared learning environment

21 century teaching and learning methods 


\section{INTIROULTION?

Learning can happen anytime, anywhere, recognition of prior learning is not in place. and the spaces where this learning occurs This clashes with the fact that the sheer are incredibly and increasingly diverse. pace of change in the 21 st century compels Education systems are undergoing a us to continue learning throughout and paradigm shift in the struggle to meet in many different areas of our lives if we the needs of learners in a world that is truly wish to understand, adapt to and, rapidly changing from a technological, most importantly, shape the world around demographic, societal and environmental us. This demands that we designate equal perspective. The rich diversity of learning value to all learning environments environments, whether within the formal whether categorised as formal, non-formal, education system or beyond in the local informal or combining varying degrees of community, workplace or civil society, is (in)formality - and reflect on how to build more valuable than ever to meet these rapidly evolving needs. Learning takes place acrossacombination of theseenvironments, hence why we see increasing reference to the term 'lifewide' learning - where people engage simultaneously in different forms of learning at the same stage of their lives.

However, these diverse learning opportunities are not equally available to all sections of society and, even when available, the outcomes of learning outside formal settings are often not regarded in the same way as those produced within them. Even the outcomes of formal learning can be difficult to transfer from one system

to another, if a robust strategy for the cooperation and seamless transitions well as more systematic and streamlined between them. Such a shift is a necessary coordination between differentministries or step towards enacting the first principle departments whose policies and initiatives of the European Pillar of Social Rights ${ }^{2}$, touch on learning environments, which meeting the objectives of the strategic may include culture, employment, health, framework for European cooperation in research, digitalisation and sustainable education and training ${ }^{3}$, and achieving the development, among others.

UN Sustainable Development Goal 4 by $2030^{4}$.

This shift is at the heart of the Lifelong Learning Platform's mission. Our policy paper seeks to encourage a debate and provide recommendations by illustrating the diversity of learning environments, the value of building these around the learner's needs, the need for robust validation arrangements for the learning outcomes that they produce and, finally, the importance of building cooperation between them.

It should be highlighted that the implementation of the following recommendations demands a robust and holistic investment in education in its wider scope (lifelong learning), which requires both the public and private sector in light of training at the workplace, as
Jackson, Norman Jeffrey (2011). Learning for a Complex World: Alifewide concept of learning, education and persona development. United States of America: Authorhouse.

2 Everyone has the right to quality and inclusive education, acquire skills that enable them to participate fully in society and manage successfully transitions in the labour market. See the full list of 20 principles here.

ET2020 Framework

Sustainable development goal 4 Ensure inclusive and equitable quality education and promote lifelong learning opportunities for all training and life-long learning in order to maintain and

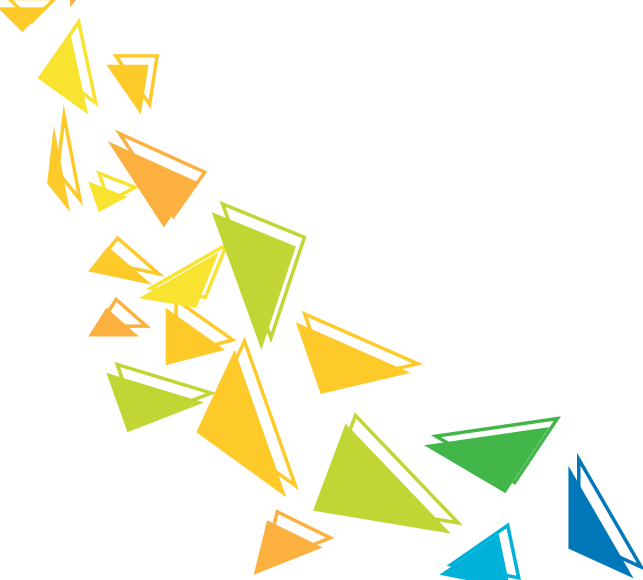




\section{MAIN RECOMMENDATIONS}

Integrate a more nuanced understanding of learning environments into education, training and lifelong learning policies, guided by the overarching principle to support learners' individual and unique potential. This means recognising, including through sustained investment, the value of learning environments beyond formal academic education as dynamic hubs of competence development - from which the latter can also draw expertise in adopting more inclusive and innovative approaches to meeting learners' needs.

FLEXIBLE PATHWAYS

Foster flexible learning pathways by supporting people in accessing and moving across learning environments as they progress through life, in accordance with their needs and regardless of age or background. This can be achieved through measures linked to modular or 'micro-learning' approaches, shorter study cycles and enhanced arrangements for the validation of prior learning of all types, as well as quality lifelong guidance which empowers individuals in managing their own learning and career paths and better reconciling their personal and professional lives. All this is crucial to boost learning motivation, avoid 'dead ends' and ensure that no learners are left behind.

LaITAL DIGITAL

Promote the purposeful use of digital and blended learning environments to offer wider and more personalised access to lifelong learning based on the understanding that they cannot replace face-to-face learning, in line with a holistic approach to personal development. This means making use of the diverse range of spaces that may support learning processes, including in the outdoors and local communities.

\section{COMMUNITY}

Upscale the concept of 'Community Lifelong Learning Centres', building on existing practices, in order to enhance integrated service delivery while catering for the learning needs of local communities. This is particularly relevant for marginalised or minority groups who are least likely to avail of lifelong learning opportunities.

\section{CO-CREATION}

Design learning environments based on a needs-centred approach, with the aim

to ensure learners' role as active co-creators of knowledge and their environment. This also means flexibility in the design and arrangement of the physical space where learning occurs and allocating resources from national and EU funds, including the future InvestEU programme, to support this across the full spectrum of education and training providers.
6 Recognise the role of teachers and educators in the 21st century as facilitators, not directors, of learning with the necessary resources, training and policies to support them in managing the rapid changes that they are facing. Recognising the reality of this new role also means integrating into our education and training policies a more contemporary understanding of who an "educator" can be, including trainers and facilitators who work with learners outside the formal environment.

PARTICIPATION

Provide concretesupportand resources for the integration of participatory pedagogy,

including collaborative, peer-to-peer, dialogic and inquiry-based approaches, in

order to ensure the active and meaningful participation of learners. More flexibility

in adapting curricula and assessment methods is a vital step towards achieving this.

COMPETENCES

Recognise that competences for the 21st century are not only digital or technical in nature but encompass learning to learn as a competence in its own right and other "life skills" which support individuals' resilience and participation in wider society. The development of such competences should be supported from the beginning of and across the lifelong learning continuum, including through investment in nonformal and informal learning environments which are particularly relevant in terms of acquiring these competences.

VALIDATION

Prioritise the implementation of arrangements for the validation of non-formal and informal learning which is imperative to give value and visibility to all learning irrespective of the environment where it takes place, especially for learners with a low level of or an adverse experience with formal education. These arrangements should be universally accessible, inspired by the key guiding principle of social equity as well as the meaningful participation of stakeholders from all sectors affected by validation processes.

\section{COOPERATION}

Systematically build cooperation and partnerships between and across formal, nonformal and informal learning environments, at regional, national and European level, including support for their representative associations at these different scales, in order to facilitate innovation transfer and foster coherent lifelong learning approaches that take into account and bring together the different aspects of individuals' lives. 


\section{SNIVIRONMPNJ?}

Before dwelling on the learning aspect, it is useful to reflect on what we understand an environment to be. More than just the space around us in any given location, an environment may be considered a multi-modal hybrid phenomena that involves social, cognitive, cultural and biological interacting modalities, as well as "relational" phenomena, i.e. there is no environment unless there are agents who interact and enact its affordances ${ }^{5}$. This is important to consider in a learning context because the learner, as an agent, is confronted with other phenomena (including other agents) and much of the learning occurs through those interactions. This evokes different notions that are discussed throughout the paper from the micro-level, such as elements related to learners' agency and the shaping and cocreation of their learning environments, to the macro- or system level, namely the policies that shape the everyday reality of earning environments and where they fit in the socio-political order.

The term "learning environment" specifically may be defined or conceptualised in different ways.

The Glossary of Educational Reform describes it as follows:
'Learning environment refers to the diverse physical locations, contexts, and cultures in which students learn. Since students may learn in a wide variety of settings, such as outside-of-school locations and outdoor environments, the term is often used as a more accurate or preferred alternative to classroom, which has more limited and traditional connotations - a room with rows of desks and a chalkboard, for example ${ }^{6}$.

The term also encompasses the culture of a school or class-its presiding ethos and characteristics, including how individuals interact with and treat one another-as well as the ways in which teachers may organize an educational setting to facilitate learning.....'

Variety in settings and contexts is fundamental because not one type of environment can have a monopoly on learning, even if the formal education system and the policies that shape it may tend to give the opposite impression. In essence, learning is a personal process which forms part of the human experience and, as such, it does not depend on formal education provisions ${ }^{7}$. The above definition also reinforces the notion of learners relating

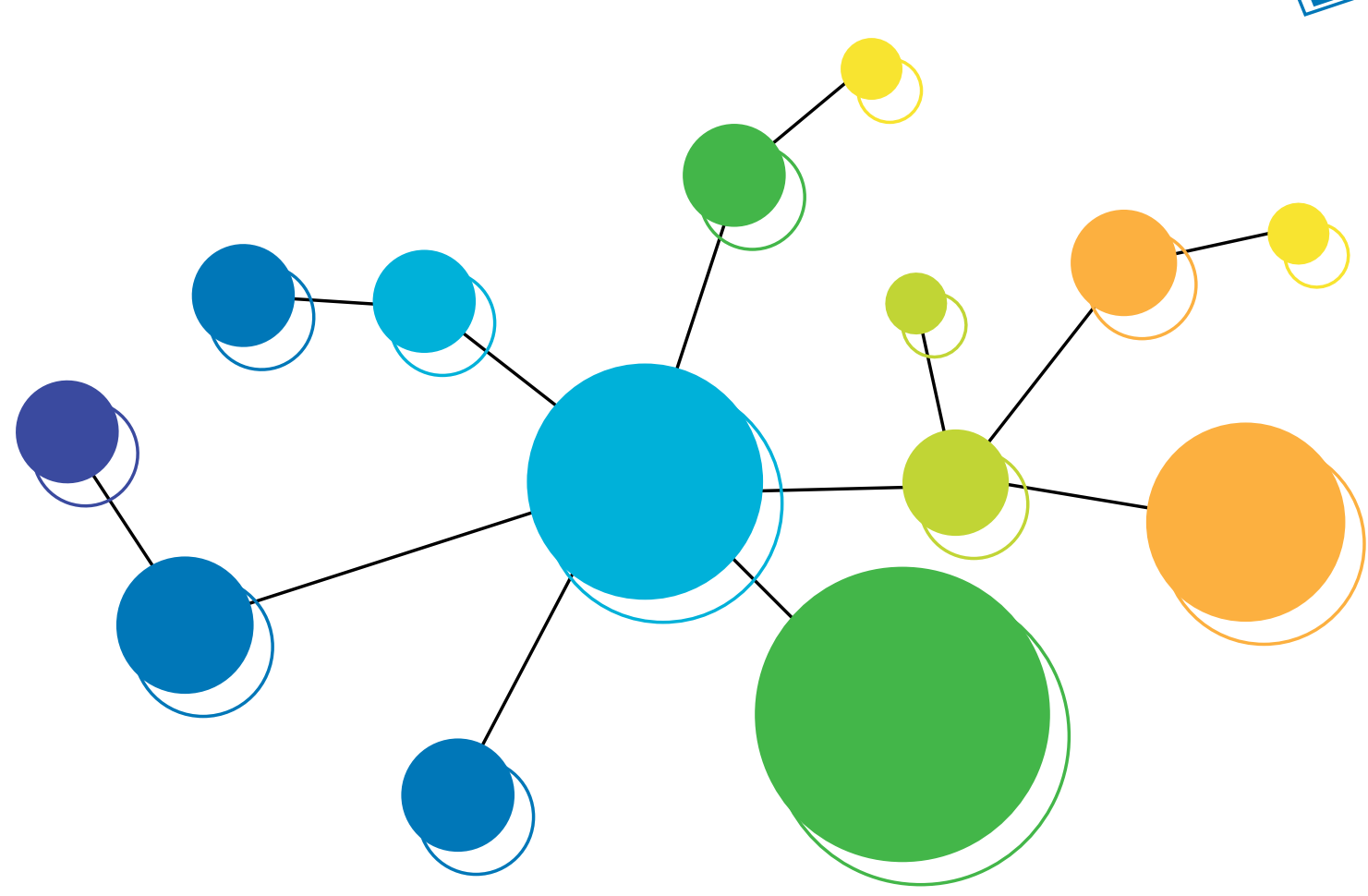

to and interacting with each other, as well as evoking the idea of how the physical space itself is arranged. These are elements analysed below when we consider how to build the learning environment around the individual with a view to maximising her or his learning potential.

The Organisation for Economic Cooperation and Development (OECD) also looks at such concepts and principles in its 2017 study on Innovative Learning Environments (ILES). Here a learning environment is described as one which "includes the activity and outcomes of learning, rather than being just a location where learning takes place" ${ }^{8}$. This calls for reflection on how learners participate in the "activity" and on what they do with the "outcomes" after their experience in any given learning environment. This is crucial when it comes to the question of what support exists at the system level for the recognition and validation of learning outcomes.

Markauskaite, L., \& Goodyear, P. (2017). Epistemic fluency and professional education: Innovation, knowledgeable Springer.

Ed Glossary, «learning environment

Billett, S. (2010) The perils of confusing lifelong learning with lifelong education. International Journal of Lifelong Education 29 (4) 401-413.

OECD (2017) Innovative Learning Environments, p.16. 


\section{SHIFTING FROM EDUCATION TO LFANTIG。 ALL LEARNIING MADE EQUAL}

Across most academic and policy contexts, to speak about the degree of formality learning tends to be categorised as or informality in learning, because these 'formal', 'non-formal' or 'informal'. Formal are characteristics present in all situations education or learning is learning that is where learning occurs?. Indeed, the organised and structured as part of a clearly boundaries between what are perceived as defined curriculum and leads to formally formal, non-formal and informal learning recognised qualifications from institutions environments are rarely clear-cut. There such as schools and universities. Due to are cases where non-formal education its official character or 'concreteness', this methods are used in the school classroom, is usually the category most privileged a distinctly formal environment ${ }^{10}$. Another by policymakers and wider society. Non- case is at universities where multiple formal learning tends to be understood as environments may sit closely side-byvoluntary learning which happens outside side for students who, besides attending this formal system but remains intentional a formal course, live in halls of residence and structured to a certain extent within which form a "vibrant and diverse all-round a programme delivered by an organisation living and learning environment" where (e.g.work-based training). Informal learning, the learning process "extends beyond on the other hand, is usually understood the classroom to involve a wide range as 'experiential' in the sense that it is not of experiences: from moving away from institutionalised, planned or structured home for the first time; to sharing a living and typically occurs through an individual's space; to participating in the wide range everyday activities and interactions (e.g. of (...) activities and programmes on offer learning among family and friends).

Of course, this is a rudimentary overview and the above categorisations are subject

to contested debate. Crucially, there is

a school of thought which questions

the utility of labelling learning in this way and considers it more accurate as part of university life"11. This transition between learning environments not only happens horizontally across different contexts ('lifewide') but also vertically through time ('lifelong') when we consider, for example, non-traditional students such as experienced workers who enroll in a formal degree programme after developing skills at the workplace. This shows that learning environments of different types are not mutually exclusive but people move between them in an infinite variety of ways.

In many respects, an understanding of this broad nature of learning environments is absent from education and training policies across the EU, or where they acknowledge this they tend to do so only superficially or inconsistently. At the EU level, for instance, although the Key Competences for Lifelong Learning Framework ${ }^{12}$ provides a strong basis, inconsistencies arise when other initiatives such as those related to the European Education Area do not address learning beyond the formal sector, or in the case of the 2018 Education and Training Monitor which looked at the acquisition of civic competences through non-formal and informal learning exclusively in terms of youth work, thus neglecting its much broader scope.

All in all, formal (academic) education still remains the main driver of the learning ecosystem, while vocational education and training, non-formal and informal learning remain, to varying degrees, secondary in esteem or recognition. Although formal education still holds an essential role in our societies, and its quality and inclusiveness should be guaranteed, a shift is needed towards a lifelong learning paradigm where supporting the individual's potential is the key guiding principle. This means equal recognition and value for all learning environments and the possibility to move seamlessly between them.

Colley, H., Hodkinson, P. \& Malcolm, J. (2003). Informality and formality in learning. a report for the Learning and Skills Research Centre.

${ }^{10}$ CARMA project

1 European University College Association (EuCA) (2012). Soft skills in action: Halls of residence as centres for life and earning.

Council Recommendation of 22 May 2018 on key competences for lifelong learning. 
The rapidly growing use of digital have their own needs and particularities, technologies has given rise to new digital the digital wave has further loosened the and blended learning environments, boundaries between them.

opening possibilities for wider access to

knowledge and more personalised learning This loosening of boundaries equally has processes ${ }^{13}$. A wealth of new opportunities a temporal dimension as learners are less for learning are available thanks to MOOCs, and less likely to fit into the linear pattern online tutoring and video platforms such of school-work-retirement. It is no longer as Youtube where one can find tutorials the norm and more needs to be done about almost everything. In fact, a 2018 to support individuals in accessing and research study in the United States found moving across learning environments as that $51 \%$ of Youtube users say that the they progress through life, in accordance website is very important for them to with their needs and regardless of age, learn how to do new things ${ }^{14}$. Not only has ableness or socio-economic background digital technology expanded opportunities Otherwise, learners with a low level of this way, it has implications for formal environments such as schools because it breaks their monopoly on the transmission of knowledge and challenges how they organise time, space and their internal structure ${ }^{15}$. It opens them to the world beyond their walls. So, although different types of learning environments will always

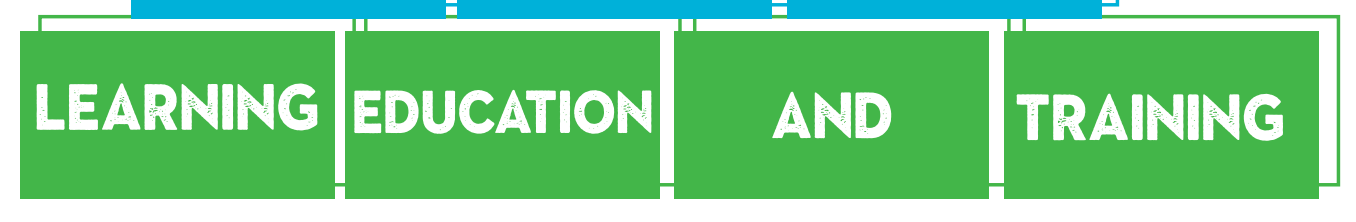
at a disadvantage. are at a disadvantage. flexible learning p a th w a y s including modular SOCIETIES THROUCH LIFELONG $\begin{aligned} & \text { or 'micro- } \\ & \text { learning' }\end{aligned}$ TRANNNG approaches, shorter study cycles, enhanced 21st century learning environments where arrangements for the validation of prior space and time are rendered flexible thanks learning of all types (more on this below) to innovative technologies, including and indeed the purposeful use of digital artificial intelligence. Despite the many tools. This flexibility is key to boost learning advantages that their carefully planned use motivation and widen access to lifelong can bring such as saving time, selection learning, so that it can fit easily into people's of the most relevant content, etc., they busy lives. When it comes to adult learning cannot replace face-to-face learning. A in particular it is difficult to imagine, without holistic approach to human development such flexibility, how an ambitious target that caters for individuals' well-being and of $25 \%$ for participation in adult learning, makes use of the full range of learning proposed by the European Commission environments available to us, not only under the vision for a European Education online but also offline, is crucial. Outdoor Area ${ }^{16}$, could be achieved while the current learning is a concrete example. There is a rate stands at a modest $11.1 \%{ }^{17}$. substantial body of evidence documenting the positive effect that learning in natural Itisacommonclaim thatthefuture oflearning environments can have on children's health, is digital, that this is the defining feature of well-being, competence development and

\section{BUILD $\begin{gathered}\text { There are various ways } \\ \text { to promote }\end{gathered}$}

\section{EUROPEAN DISTANCE E-LEARNING NETWORK (EDEN)}

The Support Future Learning Excellence through Micro-Credentialing in Higher Education (MicroHE) project aims to gather the state of the art in microcredentialing in European higher education, forecasting the impacts of continued modularisation of higher education, examining the adequacy of European recognition instruments for micro-credentials, and developing an online clearing house to facilitate recognition, transfer and portability of micro-credentials in Europe. 


\section{LOCAL COMMUNITIES: \\ A SHARED LEARNING ENIVIRONIMENT}

\section{EUROPEAN UNIVERSITY CONTINUING EDUCATION}

NETWORK (EUCEN)

Through Digital Wellbeing Educators, eucen aims to increase the capacity of lecturers and teachers to integrate digital education in a way that promotes the digital wellbeing of students. Through building teacher capacity, the project seeks to improve students' abilities to manage their online time, make the most of digital learning, critically assess the media they consume and create and become responsible, confident digital citizens.

environmental attitudes in adulthood ${ }^{18}$. In find solutions.

a lifelong learning perspective this aspect

of learning in outdoor environments, either informally or integrated into forma or non-formal education programmes, is important to consider in the face of climate change and other ecological crises as a way to foster connection with the natural world. Therefore, learning in the 21st century should not only be about adapting to digitalisation, or seeking to digitalise all learning environments, but about addressing the full array of societal challenges we are confronted with and using all possible learning spaces to help us

\begin{abstract}
Platform (2017), Reimagining Education for the Digita Age, Position Paper, P.6

${ }^{14}$ Pew Research Center (2018) «Many Turn to YouTube for Children's Content»

Plataforma para o Crescimento Sustentável (PCS) (2019) Reshaping Schools for a T-World

${ }^{16}$ European Commission (2017). Strengthening European Identity through Education and Culture: The European Commission's contribution to the Leaders meeting in European Commission (2019). Education and Trainin Monitor 2019. SWD(2019)350

Malone, K. and Waite, S. (2016) Student Outcomes and Natural Schooling. Plymouth: Plymouth University.
\end{abstract}
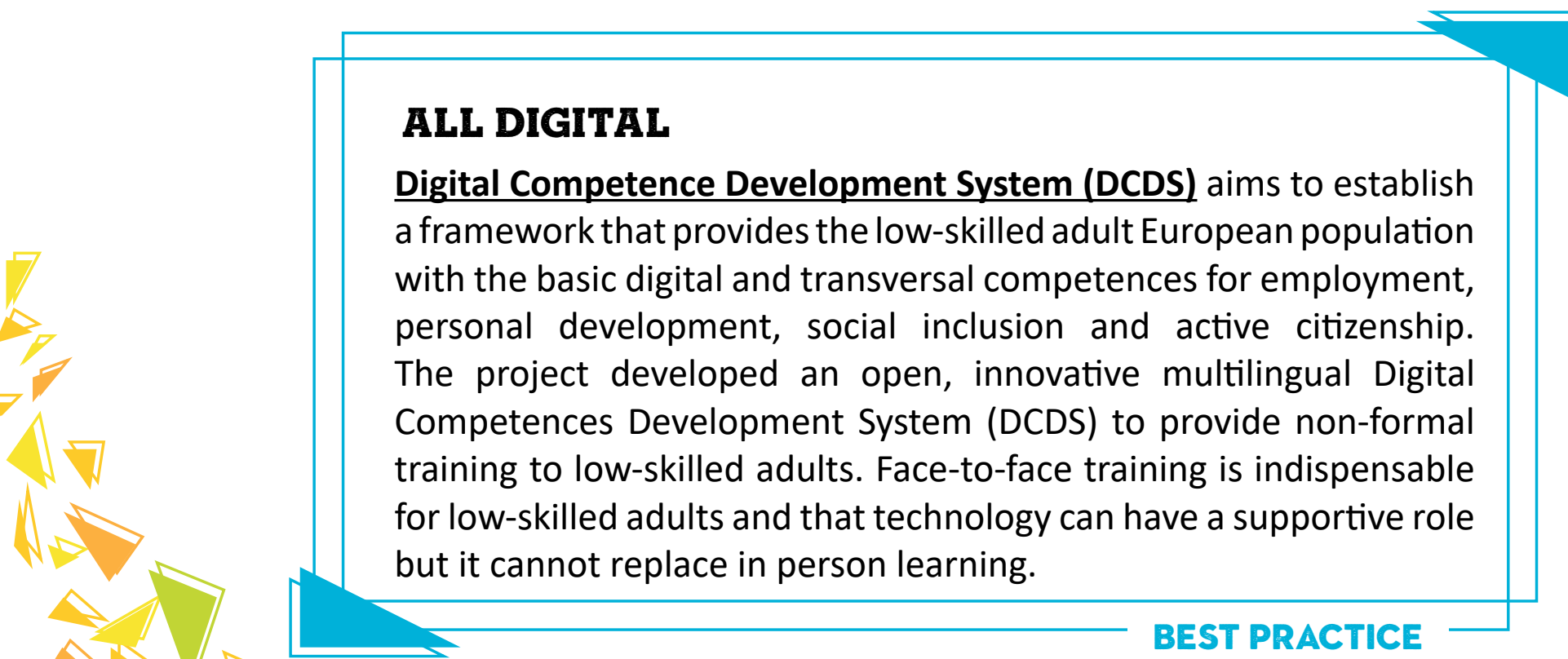

BEST PRACTICE
If the natural world can be a learning showcased at the joint Cedefop-LLLP environment, so too can our local policy forum "What role for community communities which act as vibrant hubs of lifelong learning centres? The potential of everyday activities and interactions. Formal one-stop shops for preventing youth at education institutions such as schools and risk from disconnecting" which took place universities have a general tendency to be in Brussels on 29 May 201920. It has also closed off from the communities in which been the basis for national programmes, they are located, serving only their enrolled like in Latvia where the initiative "Schools students and lying empty during evenings as Community Development Centres" was and weekends. Instead, we should implemented as a way to sustain small connect learning environments with their schools in rural areas while using them to communities and open them up to other host extracurricular and adult education users in the local area. This could be through activities ${ }^{21}$

Community Service Learning initiatives (see project below) or by establishing "Community Lifelong Learning Centres" that can cater to the needs of those people $w$ not in education, training or employment or the general public interested in further personal and professional development ${ }^{19}$ Many inspiring practices based on this concept already exist across the EU, as
The main advantage of Community Lifelong Learning Centres is that they provide a welcoming environment, often combining different modalities of learning and offering other personal and social services alongside these, which is accessible to the local community both in terms of physical proximity and as places where learners,

\section{ERASMUS STUDENT NETWORK (ESN)}

SocialErasmus is an international project by the Erasmus Student Network (ESN) that promotes a social attitude among young citizens participating in mobility programmes, to facilitate their integration into the local community while gives them the chance to make a long lasting social change in society through volunteering activities. The project goes under the slogan: Leave your mark!

\section{$\longrightarrow$}

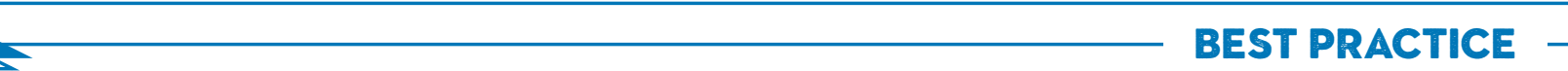

- BEST PRACTICE - 


\section{EUROPEAN UNIVERSITY FOUNDATION (EUF)}

University of Gent has developed the academic programme Community Service Learning (CSL), a form of experiential learning where students contribute to their community by participating in professor-approved community service placements related to course learning objectives and then produce corresponding reflective assignments.

BEST PRACTICE

including those from marginalised groups, feel a sense of safety and belonging. This community-centred approach is a crucia element in the vision for 21st century learning environments because it serves to open up lifelong learning opportunities at the local level, particularly for those individuals least likely to participate in formal education programmes.

\section{EUROPEAN SCHOOL HEADS ASSOCIATION (ESHA)}

'Open Schools for Open Societies' aims to help a thousand European primary and secondaryschools with opening up to their communities. An "open school" is a more engaging environment for students and raises their motivation by connecting student projects with real needs from the community and drawing upon local expertise. The project includes the production of guidelines on designing partnerships with local industries, research organisations, parent associations and policy makers.

\section{BUILD THE ENVIRONMENT

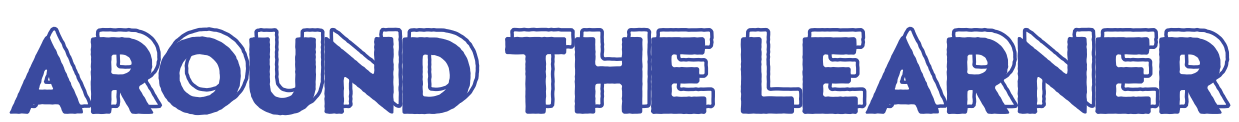

According to the OECD, the first principle of an innovative learning environment is that its "recognises the learners as its core participants, encourages their active engagement and develops in them an understanding of their own activity as learners" (emphasis added)22. It follows that learners should be at the centre of all considerations when it comes to designing and supporting learning environments, whether at the micro- or macro-level. Attention must be paid to ensuring their role as active co-creators of knowledge and their environment, avoiding the outdated idea of learners as passive listeners who fit into rigid, pre-defined models and spaces. This means that the environment should foster learners' "agency", understood broadly as the sense that they are doing or are able to do things, rather than things just happening to them: in other words, a sense of efficacy ${ }^{23}$.

Crucially, to develop agency the learner "needs to be treated as an active subject, not just an object of upbringing or education"24. This means looking at the learner's intrinsic potential and enabling him or her to discover and harness this

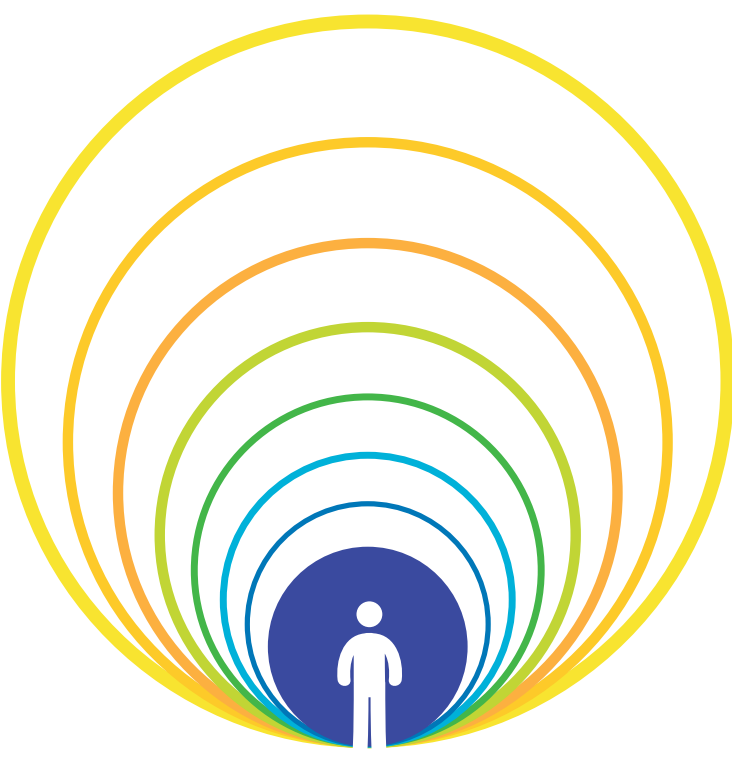

potential, no matter his or her past or background. This is especially relevant for individuals with adverse prior experience of the formal education system which, in many cases, may have eroded their sense of efficacy by failing to adequately respond to their needs. On the other hand, learning environments beyond the formal sphere tend to be more needs-sensitive, as a general rule. For instance, in the context of children from a migrant background, nonformal educators can better adjust to the needs of individual learners because they are not restricted by national curricula and timetables, claims one study ${ }^{25}$. In general, non-formal education can positively

\section{SOLIDAR FOUNDATION}

The Collaborative Learning Action Network (CLAN) project was launched to enable low-skilled adults to identify transversal skills acquired throughout their lives and not validated in their lives, using information and communication technologies. The project presents a new methodological approach with individual's interests and motivations as the main target upon which the whole process will take place. 
influence a learner's confidence by vocational colleges, adult education enhancing self-esteem, self-awareness and centres, community and volunteer-based motivation to learn ${ }^{26}$. Likewise, informal associations, all of which usually struggle learning can help to create a more to access this kind of investment. Support personally meaningful learning experience for spatial and infrastructural flexibility in which is built around individual needs, all types of learning environment is key to goals and expectation $\mathbf{s}^{27}$. Of course, this guarantee the diversity of learner-centred, does not mean all learning environments lifelong learning provision. We also see this beyond the formal system are inherently as a potential area of intervention for the good (and the latter inherently bad) or offer 'Social investment and skills' window of the a panacea for meeting learners' needs, but future InvestEU programme. it highlights the imperative to recognise and take seriously the potential added value they bring to the learner's experience, either in their own right or by incorporating some of their approaches into the formal domain.

Promoting the learner's agency may also be achieved through the physical design of her or his environment. For example, it is increasingly accepted that the traditional way of organising the school classroom with the teacher at the front and students seated in rows for a whole lesson is not optimum for supporting innovative pedagogical approaches ${ }^{28}$. Building the environment around the learners' needs thus calls for more flexible infrastructure. The benefits of this are proven, for example, by the 'Clever Classrooms' initiative in the UK which showed that differences in the physical characteristics of classrooms, including air quality, colour and light, can boost the learning progress of primary school pupils by as much as $16 \%$ in a single year ${ }^{29}$. Evidently, supporting such flexible learning environments requires targeted resources. However, these resources cannot be directed only towards general schools as other spaces equally stand to benefit from more flexible and innovative infrastructure includ i n

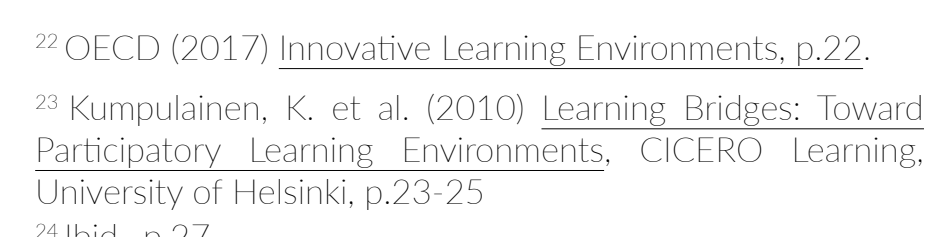
Participatory Learning Environments, CICERO Lowar ${ }_{4}^{4}$ bid., p.27.

Bislimi, F. et. al. (2017) Education and Skills Developmen in the Context of Forced Migration, Policy Brief developed by the T20 Task Force on Forced Migration education and the role of $\frac{1 \text { NGOs in its promotion", Article for }}{\text { NGOrlance of }}$ the 7 th edition of the International Conference 'European Workshop.

Petkovic, S. (2018). Desk study on the value of informa education, with special attention to its contribution to dialogue and learning, European citizenship, peace-building and conflict transformation. Commis

${ }^{3}$ European Schoolnet (2017) Guidelines on Exploring and Adapting Learning Spaces in Schools.

Barret, P. et al. (2015) Clever Classrooms: Summary Report of the HEAD Project (Holistic Evidence and Design).

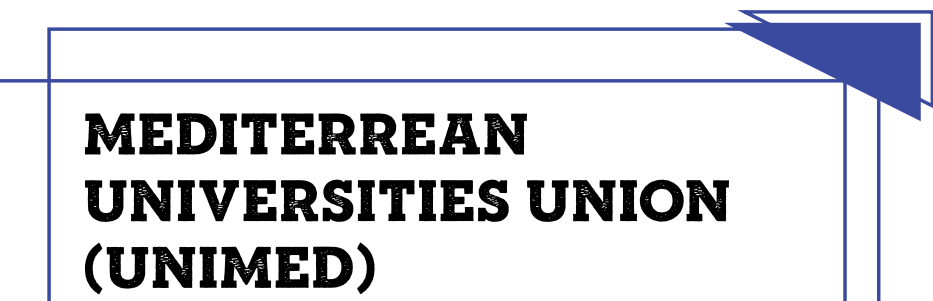

(MED)

The Upskilling Refugees and Adult Educators (UPGRADE) project aims to develop innovative training resources for refugee and migrant adults with low skills, as well as educators working with these populations, in order to support their integration in the EU labour market.

\section{WHO CONTROLS THE ENVIRONMENT?}

In the 21st century, the role of teachers and educators is obliged to rapidly evolve, in large part due to the technological changes mentioned above which mean they are no longer the definitive source of knowledge which they were in the past. They are becoming "gatekeepers of the learning process rather than the content" 30 Moreover, in a flexible environment where learners become active agents it follows that the teacher's position within that environment, including during interactions with the learners, must be reimagined. To support agency, like the arrangement of the physical space, teachers may adapt how they are positioned vis-à-vis the learners, for example, by sitting among them, allowing one of them be the chair of the lesson and putting up their hands like the others, changing rules about who has the right to move around in class or write on the blackboard or whiteboard etc.. ${ }^{31}$ They should adapt their pedagogical approach with the aim to facilitate learning rather than direct it. Again this relates to how they set up and navigate the space of the learning environment as teachers "use space to underscore their learning intentions and personal belief sets" 32

Atthe macro- level, a broader understanding of how we define a teacher or educato should be reflected in education and training policies. Non-formal educators, community or volunteer facilitators, trainers, youth workers, parents, among several others, are equally gatekeepers of the learning process and must be recognised as education stakeholders and for the valuable work that they do in sustaining the diverse range of learning

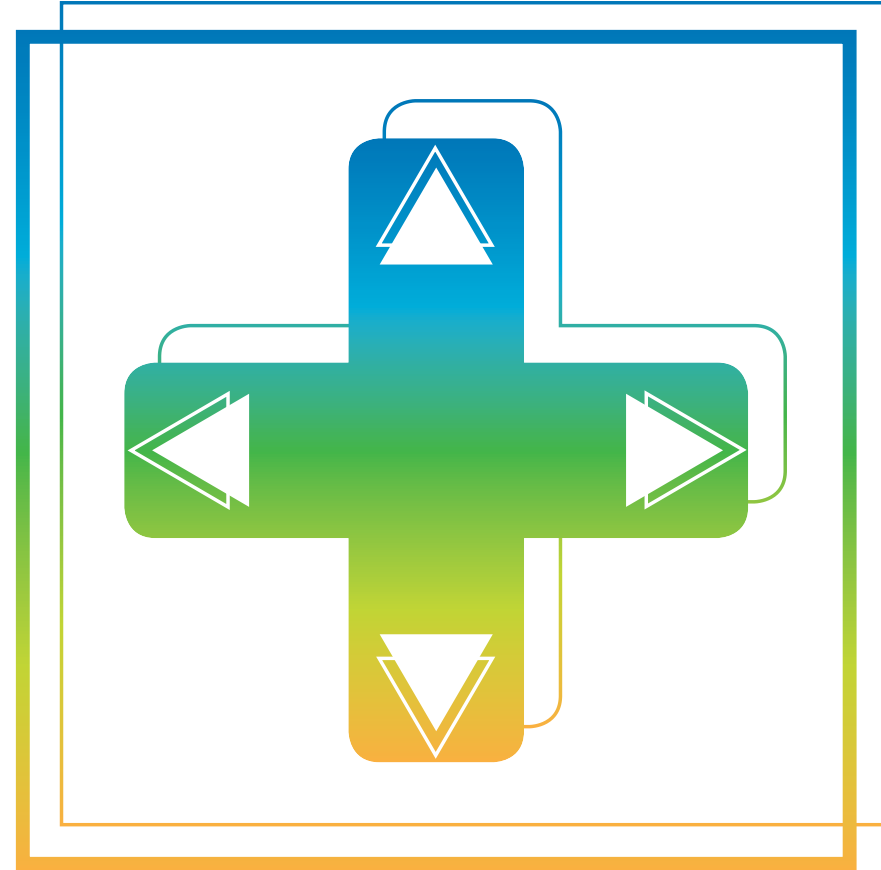

environments in society for people of al ages. In addition, in the 21stcentury it makes sense to bring the 'real world' more into formal learning environments by adopting 


\section{ST CENTURY TEACHING AND LEARNING METHODS}

the practice of inviting 'guest teachers' Optimising the potential of learners across into the classroom or lecture theatre, for all environments, and building these example, experts from civil society, the around their needs, simply calls for a more business sector including SMEs and start- flexible, open-minded approach in how we ups, political representatives or even the conceive the student-teacher relationship students' family members. This shows that, and who we regard as supportive agents in informally, we all have the potential to be the learning process.

an educator.

Such approaches should not be construed as an attempt to undermine the role of teachers or professional educators. They will always play a crucial guiding role and have the right to high-quality working conditions, initial training and continuous professional development in order to adjust the environments that they facilitate to the demands of the modern world and meet learners' individual needs.

30 Plataforma para o Crescimento Sustentável (PCS) (2019) Reshaping Schools for a T-World, p.26

${ }^{1}$ Kumpulainen, $K$. et al. (2010) Learning Bridges: Toward Participatory Learning Environments, CICERO Learning. University of Learning Envin 32 Lucas, B., Claxton, G. and Spencer, E. (2013). Expansive
Education: Teaching Learners for the Real World, p.15.

\section{EUROPEAN ASSOCIATION FOR HISTORY EDUCATORS (EUROCLIO)}

The Learning to Disagree project aims to support educators in how to constructively discuss controversial topics by developing teaching materials and guidelines and enabling students to acquire social and civic competences through debates and dialogue on such issues.
Learning environments are shaped participatory pedagogy across formal, nonaccording to the approaches and practices formal and informal learning environments that take place within them. As the above and its value has long been championed by principle outlined by the OECD highlights, researchers and civil society, yet the extent innovative learning environments foster the to which it has been integrated at the "active engagement" of learners, otherwise macro-level as a central tenet of education they can hardly be expected to participate and training policies, with the necessary in a meaningful way. They work with a mix support and training for educators, is of pedagogical approaches, many of which questionable. The training question is also are based on collaborativeworkandinquiry- important when it comes to the use of based learning ${ }^{33}$. Interactions within the digital tools which have the potential to environment need to foster learner agency support innovative pedagogies. However, and initiative rather than the acquisition of there is often a lack of sufficient support ready-made contents, which means raising from policymakers or, where it does exist, expectations of active participation and it is rarely guided by a long-term strategy. taking learners seriously as interlocutors who contribute to meaning creation. Thus, In addition, the further integration of the possibility of creating knowledge on these participatory methods would benefit their own and having a say in the choice from giving more autonomy to formal of contents through dialogic inquiry can education environments to design and enhance learners' engagement ${ }^{34}$. Here apply the curriculum and explore new mutual interaction is also an important assessment methods, not only summative element to consider, recalling the value but formative or combined ${ }^{35}$, where the of peer-to-peer learning as an approach in acquisition of knowledge is not only developing learners' agency.

There are good practices of such the predominant assessment method and, 


\section{GIVING LEARNERS A TOOLKIT FOR THE 21ST CENTURY}

EUROPEĀN UNIVERSITY COLLEGE ĀSSOCIATION (EUCĀ)

The Learning and Interacting to Foster Employability (eLene4Life) project supports curriculum innovation in higher education through the development of active learning approaches for soft skills, with the aim to improve students' employability. Teachers will receive support in pedagogical innovation and the transformation of teaching practices, with the ultimate goal of improving the learning experience of students.

\section{BEST PRACTICE}

besides reinforcing competition among 21st century learning environments. learners from an early age, it is increasingly criticised for the fact that it privileges the agency of (young) learners who are born with a certain cultural capital against those coming from disadvantaged backgrounds, hence contributing to early school leaving, inequality of opportunities and limited socia mobility ${ }^{36}$. Some countries in Northern Europe are moving away from the grading system but elsewhere in Europe, there is little questioning of grading systems and their impact on learners, including attitudes towards learning in general. We thus consider flexibility in this area as a prerequisite for supporting the shift towards

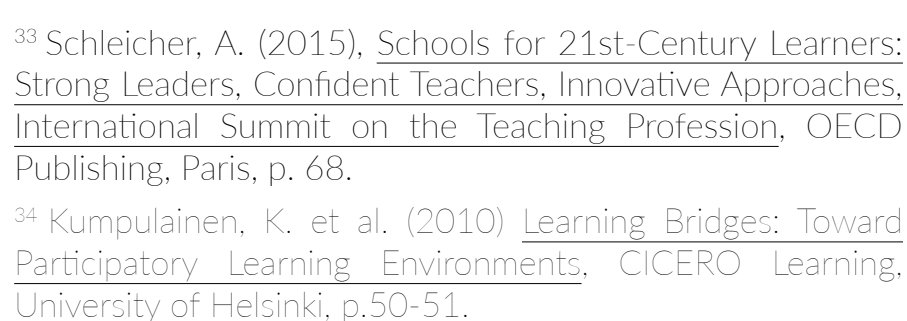

${ }^{35}$ Innoval "Innovative assessment for validation" project, 2016-2018, Erasmus

6 Bourdieu, P. and Passeron, J. (1990) Reproduction in Education, Society and Culture (Theory, Culture and Society Serérie du systèm. La Reproduction. Eléments pour une 1970)
As outlined above, a learning environment learning environments should aim to should foster learners' understanding of support individuals in identifying, exploring their own activity as learners. This evokes and developing the optimum ways in which the notion of "self-regulated learning", they themselves engage in the learning i.e. the conscious planning, monitoring, process, in a spirit of self-discovery and evaluation and control of one's learning in avoiding a one-size-fits-all approach. order to maximise it ${ }^{37}$. It also relates to how

we approach learning as a competence Learning to learn is not the only in its own right. In order to ensure competence that learners need in their individuals' resilience and ability to adapt toolkit for 21st century life. Indeed, "21st to social, economic and other forms of century" competences, including creativity, change, they must learn how to learn - problem-solving, leadership, empathy this is a prerequisite for acquiring all other and communication, to name just a few, competences, and sets the foundation are increasingly in demand in the context for lifelong learning. It is the ultimate of rapidly changing societies and labour survival tool for living in the 21st century. markets ${ }^{38}$. For instance, a report by the Therefore, from early childhood onwards, McKinsey Global Institute predicts that

EUROPEAN FORUM OF TECHNICAL AND VOCATIONAL EDUCATION AND TRAINING (EFVET)

The Innovative Curriculum on Soft Skills for Adult Learners (ICARO) is a project aimed at developing a training curriculum on soft skills for unemployed adult learners to support their (re)integration in the labour market. The project has also developed an assessment tool for soft skills. 
demand among employers for "social engagementwith the widerworld, including and emotional skills" such as negotiation, participation in civic life at the local, leadership and initiative-taking, will rise national and global level, if we consider by $22 \%$ by 2030 . What they term "higher competences such as the ability to critically cognitive skills" will also be highly sought engage with different perspectives or after, with creativity expected to rise in understand and respect social and cultural demand by $30 \%{ }^{39}$. Indeed, as the labour diversity. This further reveals the broader market is changing so rapidly, and many societal purpose of learning environments young learners are likely to end up working next to meeting individuals' learning needs. in professions that do not exist yet, it is more sustainable to invest in competences Reflecting on how learning environments that will help them navigate and adapt promote the development of this full range to shifting contexts instead of only those of competences again requires looking at related to technical, occupation-specific howisthis supported bytheir diversity. Nonfields. Beyond employment matters, 21st formal and informal learning environments, century competences support learners' in light of their flexibility, tendency towards

\section{EUROPEAN EDUCATIONAL EXCHANGES - YOUTH FOR UNDERSTANDING (EEE-YFU) AND ORGANISING BUREAU OF EUROPEAN SCHOOL STUDENT UNIONS (OBESSU)}

The project Coloured Glasses Grow: Expanding Intercultural Education (CGrow) was developed to expand the 'Coloured Glasses' methodology which is based on helping young people acquire intercultural and global citizenship competences through a series of workshops where they examine their attitudes towards their own cultures as well as other cultures and engage with issues related to intercultural communication, stereotyping, prejudice, and discrimination. learner-centredness and proximity to 'real life', can benefit people of all ages in this
respect. For instance, there are studies highlighting the valuable role of non-forma education in the positive socialisation of children, including such competences as communication, self-sufficiency and selfconfidence ${ }^{40}$. Extracurricular activities have demonstrated the ability to help students develop skills such as problem-solving, teamwork and resilience ${ }^{41}$. Non-formal adult education is also key in supporting older learners to acquire the full range of "life skills", covering those competences mentioned above as well as basic numeracy and literacy skills, health and financial literacy, etc ${ }^{42}$. Investing in environments beyond the formal sector can therefore bring added value to lifelong competence development, providing people with the necessary toolkit to navigate the uncertainties and complexities of 21st century life.

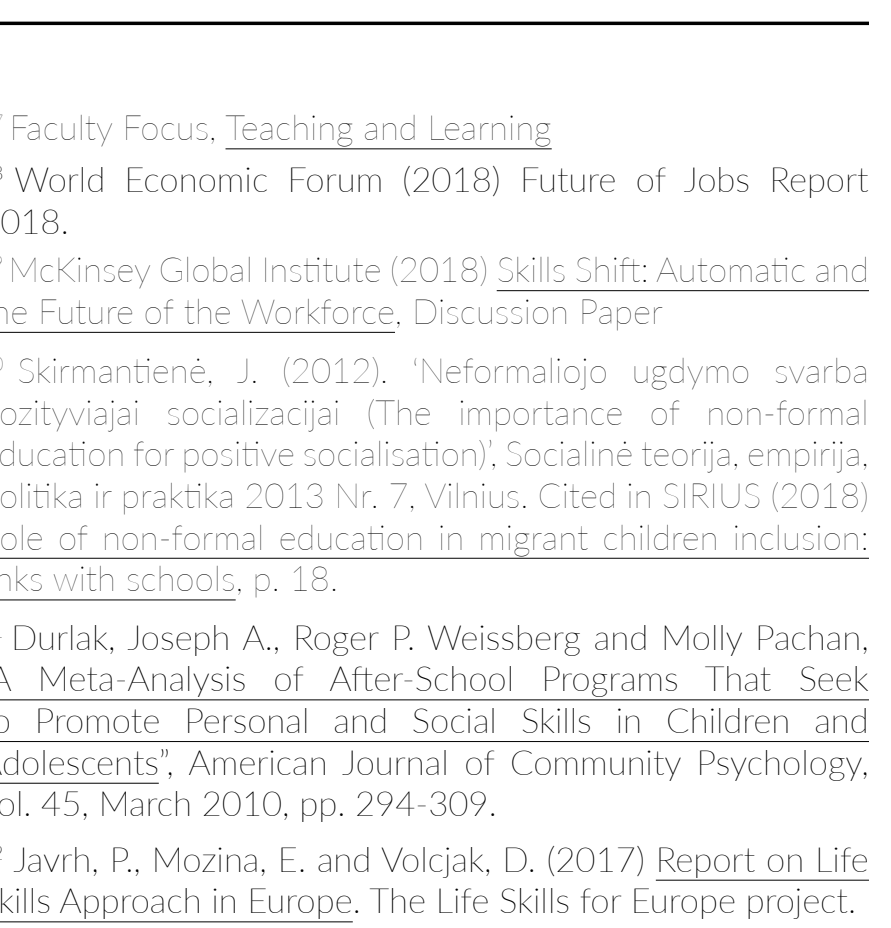

\section{EUROPEAN ASSOCIATION FOR THE}

\section{EDUCATION OF ADULTS (EAEA)}

The Life Skills for Europe project seeks to improve basic skills provision in Europe by explaining, further developing and upscaling a "life skills" approach. It has developed an overarching life skills learning framework and modules that are transferable across Europe, with a particular focus on people from a disadvantaged background, refugees and people resistant to intercultural exchange. 


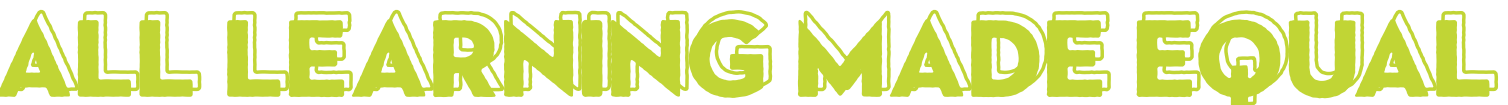

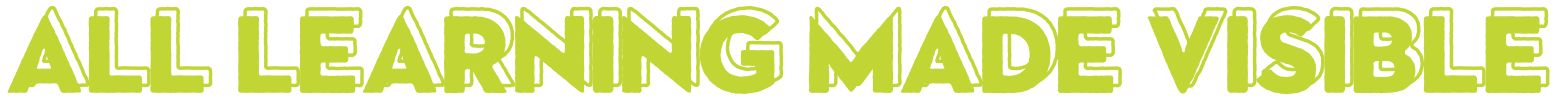

The knowledge and competences that Council recommendation on the validation individuals acquire in non-formal and of non-formal and informal learning informal learning environments are not brought a new impetus to the issue $e^{44}$, yet always accorded sufficient value orvisibility. most Member States lack a strategic vision This is problematic because it deprives and have lagged behind in their efforts to people of the opportunity to understand implement the Recommendation. and communicate their learning or use their competences to participate in further The Recommendation allows progress learning or the labour market, besides towards a common and shared perpetuating a view of formal learning understanding of validation between environments as the sole provider of EU Member States and between knowledge and competences. Indeed, stakeholders. It states that the the fact that learning environments are validation process is composed of four so diverse means that we need robust steps: identification, documentation, systems in place for the validation ${ }^{43}$ of assessment and certification. If the competences obtained in such varied Council Recommendation specifically contexts in order to give all learning the targets non-formal and informal visibility and value deserved. This becomes learning, it is because validation particularly true in the digital age where in formal education is already most competences are acquired outside institutionalised whereas of the compulsory education, and it is true making competences for a lot of other areas on which information visiblein otherlearning has been made much more readily available environments through communication and information remains a key technology. Inaddition, learnersspendmuch chall e nge of their time in family, community and in EU outdoor activities, often cultural, sport or volunteering, during which they acquire

a number of "soft skills". So far validation arrangement systems only partially exist. In the EU, the 2012 countries. Nevertheless, the recognition of prior learning at higher education level remains yet another challenge for most institutions across the EU.

Most EU countries are still in the process of developing their national qualification frameworks, whereas some already have put in place validation systems to recognise learning from non-formal or informal learning environments, such as volunteering and work-based learning, for instance ${ }^{45}$. In the validation of prior learning, some universities give credit for people to access higher education without necessarily having walked the traditional pathway. Putting in place systems of validation helps make the transition in the labour market more fluid and flexible, and therefore reinforces economic growth and competitiveness.

\section{EUROPEAN ASSOCIATION FOR THE \\ EDUCATION OF ADULTS (EAEA)}

The Transnational Peer Review for Quality Assurance in Validation of Non-Formal and Informal Learning is a project aimed at increasing the transparency, market relevance, consistency and transferability of VNFIL across Europe. It supports both Member State VNFIL systems by providing a common framework and tools, as well as transnational use of VNFIL by increasing mutual trust at the European level. 


\section{EUROPEAN VOCATIONAL TRAINING ASSOCIATION (EVTA)}

Italian member ENAIP has a project on Validating Integration Competences of Refugees (VIC) aimed at analysing existing integration measures for refugees and then provide educators working with refugees with the tools to promote, plan, actively develop and validate "integration skills" within the target group.

usability of validation tools for all learners in differentenvironments, abroad repertoire of innovative methods or approaches, such as formative and practice-based assessment digital storytelling, video- or game- based assessments, or any methods that involve supporting individuals during the process, hence mitigating learner's anxiety, must be developed, shared and transferred across learning environments. Anxiety, resulting from the feeling of incoming failure, leads to adverse experience with education, and negatively impacts individuals' learning to learn competence and their positive attitude towards learning throughout life 48 Validation of non-formal and informal learning also brings individuals many benefits in terms of self-confidence and encourages lifelong learning. After all, it is shown that giving individuals with a low level of education the willingness to learn again after an adverse school experience, is much more efficient to get them into earning than individuals with a higher level of education ${ }^{49}$.

Furthermore, validation of the learning In terms of European cooperation, the varying definitions and perceptions of the outputs of specific projects validation between Member States hinders and serve as a reference point for the development of policies based on policymakers. common understanding of key quality principles such as validity, reliability, transparency, trust-worthiness or cost efficiency. This limits the transferability of innovative methods, a situation furthe complicated by the fact that good practices emerging from validation projects, many funded by the Erasmus+ programme and a few from the European Social Fund, fail to inspire policy reform due to limited dissemination capacity. This underexploitation leads to a continuous cycle of small-scale projects working on similar topics. Besides enhanced budget within such projects for dissemination purposes, a possible remedy would be an EU community of validation practitioners which could not only exchange practices on how to give visibility to learning outcomes from nonformal and informal environments, but also synthesise and find links between

\section{INTERNATIONAL FEDERATION OF CENTERS FOR TRAINING IN ACTIVE EDUCATION METHODS (FICEMEA)}

Belgian member Ceméa has a project on Volunteering Youth: routes and tools for Competence's Emersion (VOYCE) aiming to identify practical tools to validate the learning of volunteers, enhance the use of such tools among the organisations that deal with young volunteers, and make sure the learning acquired is easily accessible by companies and usable on the labour market. 


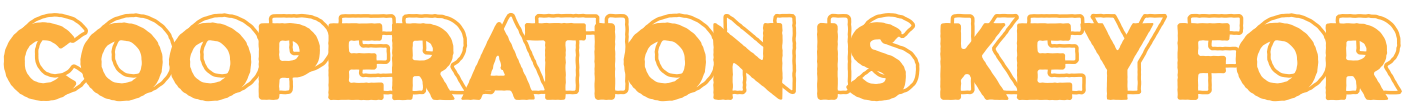

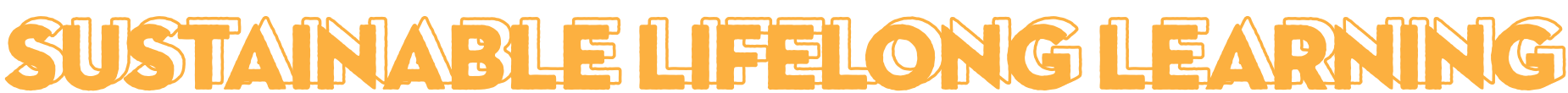

The Council Recommendation for the EU The importance of cooperation not only Key Competences Framework calls on applies to learning environments of Member States to support the acquisition of different modalities (formal/non-formal/ these competences through, among other informal) but also those of the same type. In actions, "reinforcing collaboration between fact, this is reflected in the basic legislation education, training and learning settings at all levels, and in different fields, to improve the continuity of learner competence development and the development of innovative learning approaches"50. The rationale for this is clear, as learning should connect with all of the learner's life world and 'funds of knowledge' which, evidently, surpass the boundaries of the formal environment ${ }^{51}$. If the latter fails to connect learning across contexts, there is a risk that it becomes isolated from the rest of the world and separates knowledge from its "actual context of use" 52 .This is a daunting scenario because it leaves learners illprepared for the growing complexities and challenges of the 21st century world. In addition, non-formal and informal learning environments, for example, in the form of after-school activities for young learners, can serve as a bridge or "border zone" between the culture of the school and peers, families and communities

Hence, fostering cooperation between all these different spaces is crucial.

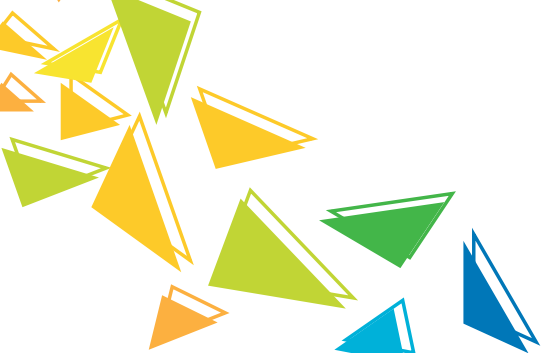

both within and across different sectors.

More networking between learning environments is required considering, for example, that schools, vocational colleges formal, non-formal and informal sectors. and civil society organisations in remote This interconnectedness should be seen as or disadvantaged regions often find a defining feature of 21st century learning themselves isolated from their peers. environments.

All in all, an alternative perception of But how to achieve those partnerships? learning environments needs to be One possibility is more activities organised embedded in the design of education at European and national level where policies as non-formal and informal policymakers and practitioners learn learning spaces are still often regarded as about good practices in building bridges purely recreational rather than dynamic and between different learning environments. strategic hubs of competence development For instance, in recent years LLLP, as a pan- from which formal environments can also European umbrella network of civil society draw expertise in adopting more inclusive organisations, has collaborated with the and innovative approaches. The EU and European Commission in organising peer the Member States should encourage and learning activities ${ }^{54}$ which have showcased support more partnerships between the the added value of cooperation with civil

\section{LEARNING FOR WELL-BEING FOUNDATION (L4WB-F)}

The Act2Gether initiative is a global movement to create partnerships between generations, across all sectors, such as Health, Education, Governance, Art, Sports, Religion, Welfare and Justice. Setting the example of a holistic approach by including the transformative power of children. Act2Gether consists of:

- GetherLand: Gatherings for all ages to play with the serious challenges in our world today

- GetherLearn: Training that helps children and adults to be better partners

- GetherLink: Online Platform for a global community sharing stories of partnership 
society for education, both policymaking and practice, bringing new and much At the national level, the tradition of appreciated insights for Member State cooperation between formal, non-formal representatives. The future generation and informal learning environments varies of the EU's Education and Training 2020 greatly from one Member State to another framework could further facilitate such and often lacks structure or strategic vision. exchanges and encourage the Member A possible remedy which LLLP has explored States to mainstream them into their and conducted preliminary research on policies on education, training and lifelong is the establishment of "national lifelong learning. This is echoed by the European learning platforms", in other words, Parliament in its explicit call to the cross-sectoral alliances of stakeholders Commission to "build closer cooperation in the field of education, training and and dialogue with representatives of civil skills to support the implementation of society, recognising that their experience national lifelong learning strategies ${ }^{56}$. This on the ground is essential to achieving the resonates with the work carried out by the ET2020 goals" 55

\section{LIFELONG LEARNING PLATFORM (LLLP)}

The LLL-HUB project aimed to create a feeling of shared responsibility on EU lifelong learning strategies through a multilateral network and ownership among relevant stakeholders (Europe 2020 headline targets, ET2020, European Semester Country-Specific Recommendations...). This was achieved by fostering national and transnational public spaces for debates and mutual policy learning, involving the grassroots level in a genuine reflection with decision-makers on the design and implementation of coherent and comprehensive lifelong learning strategies.

to elaborate skills strategies by involving a wide range of stakeholders, policy-makers, experts, civil society, etc ${ }^{57}$. Depending on the national context, there could also be such platforms at the regional level. Overall, they would serve as a useful focal point for policymakers when conducting consultations, gathering expertise in how to adapt policies and resources to the diversity of learning environments while also, and just as importantly, supporting deeper cooperation and knowledge transfer among them. A pilot scheme could be funded through the European Social Fund or its successor programme.

A further area of cooperation which would bring significant innovation to learning environments concerns coordination at the policy level between different national ministries and Directorate-Generals of the European Commission. Education, training and lifelong learning are not only directly beneficial in themselves for individuals well-being and personal development but are crucial enablers for social inclusion, culture, health, employment, research, innovation, digital transformation and sustainable development. This transversal value of learning merits a more integrated policy approach where experts and policymakers from different departments regularly communicate with and learn from each other ${ }^{58}$. Such a systems approach is even adopted and recommended by international institutions ${ }^{59}$. They clearly see value in its potential to strengthen education systems through evidence-based policymaking. To support its implementation this integrated policy approach should go hand in hand with a greater flexible allocation of resources to lifelong learning in all its diversity across funding programmes at the national and European level, including in the EU budget for 2021-202760

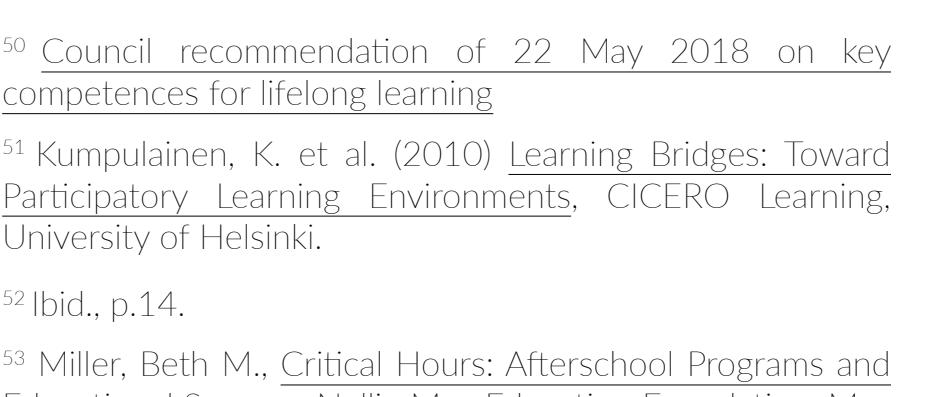
3 Miller, Beth M., Critical Hours: Afterschool Programs and 2003

${ }^{4}$ September 2017 EQF Advisory Group PLA on the role of on-governmental stakeholders in implementing the 2012 Council Recommendation on the validation of non-formal and informal learning (Lisbon); January 2018 EQF Advisory Group PLA on Validating and valuing transversal skills and competences acquired by adults through volunteering and other non-formal learning opportunities (Brussels); Apri 2019 ET2020 Thematic Working Group on Promoting Common Values and Inclusive Education PLA on cooperation between education institutions and civil society (Zagreb).

European Parliament 2016 report on the follow-up of the and training (ET2020).

Lifelong Learning Platform (2018) Feasibility Study for National Lifelong Learning Platforms.

\section{OECD, Nationals SKills Strategies}

OECD (2016) Governing Education in a Complex World. The World Bank developed the Systems Approach for comparative data and knowledge an education policies and institutions, with the aim f helping countries systematicaty trengthen their education systems and the ultimate goal of promoting Learning for All.

Lifelong Learning Platform, MFF Reaction. 


\section{LIFELONG LARNING PLATFORM \\ EUROPEAN CIVIL SOCIETY FOR EDUCATION}

The Lifelong Learning Platform is an umbrella that gathers 42 European organisations active in the field of education, training and youth. Currently these networks represent more than 50000 educational institutions and associations covering all sectors of formal, non-formal and informal learning. Their members reach out to several millions of beneficiaries.

Rue de l'industrie, 10 - 1000 Brussels, Belgium info@lllplatform.eu - +32 28932515 www.Illplatform.eu

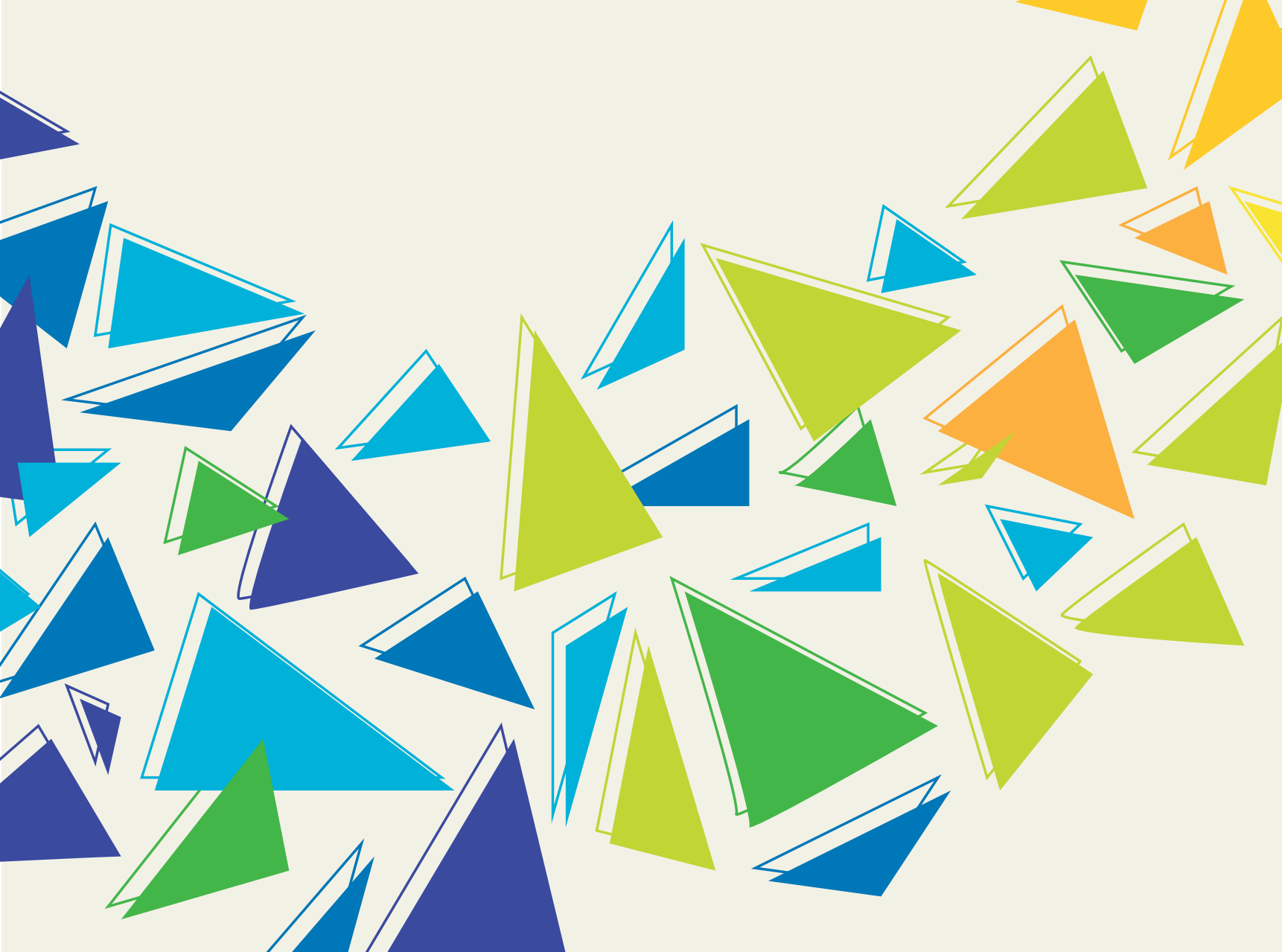

